\title{
Crise, Estado social e desafios do sindicalismo. Breve reflexão sobre a Europa
}

\section{Crisis, welfare state and challenges for trade unionism: brief reflection on Europe}

\author{
Elísio Estanque ${ }^{2}$
}

\begin{abstract}
RESUMO
Atualmente a questão sindical encontra-se numa encruzilhada da qual dificilmente sairá sem sofrer danos profundos no seu actual modelo. $\mathrm{Na}$ verdade, o sindicalismo tradicional - mesmo aquele que sempre se reivindicou de sindicalismo "de classe" - vem desde há muito dando sinais de esgotamento. Considerando a Europa e todo o seu legado social, é impossível qualquer reflexão sobre este assunto sem, ao mesmo tempo, dar conta das principais linhas de mudança que ocorreram no velho continente desde as primeiras décadas do século XX, tanto no plano sociolaboral como na esfera política e da actividade do Estado. O movimento sindical europeu bateu-se pelos direitos laborais e participou nas mais intensas lutas anticapitalistas do século XIX, mas acabou tomando parte do compromisso histórico que fabricou (à sombra do Estado-providência) as "classes médias" e levou ao poder a social-democracia. Ao mesmo tempo, não conseguiu acompanhar a dinâmica que transformou o trabalho e que germinou sucessivos movimentos sociais fora do seu controlo. Desde os anos sessenta às actuais lutas contra a precariedade e os défices democráticos, passando pelos movimentos antiglobalização neoliberal e terminando nos novos activismos dos "ciberespaços”, as novas linguagens e repertórios que mais mobilizaram a juventude
\end{abstract}

${ }^{1} \mathrm{O}$ presente texto está também publicado, com ligeiras adaptações (nomeadamente sem a parte relativa ao Estado social, incluída nesta versão), na coletânea, organizada por E. Estanque e Leonardo Mello e Silva, Facetas do Trabalho na Contemporaneidade: Diálogos Luso-Brasileiros. Curitiba: Editora Appris, sob o título "Trabalho, classe média e sindicalismo".

${ }^{2}$ Doutor em Sociologia pela Universidade de Coimbra. Professor e pesquisador do Centro de Estudos Sociais / Faculdade de Economia da Universidade de Coimbra - Portugal. URL: <http:// www.elisioestanque.blogspot. com>. Professor visitante na UNICAMP (Universidade Estadual de Campinas, SP - Brasil), Departamento de Sociologia do IFCH e pesquisador do CESIT-Centro de Estudos Sindicais e de Economia do Trabalho/Instituto de Economia (ano de 2013). 
em diferentes gerações foram, ou são, experiências relativamente laterais às estruturas sindicais e suas lideranças. Será que a intensidade da actual crise e a sua pressão esmagadora sobre o mundo do trabalho - e as classes médias europeias - fará despertar os sindicatos e retirá-los do colete de forças burocrático em que se deixaram enredar? Partindo desta realidade, o presente texto pretende traçar um balanço crítico do sindicalismo mundial e questionar os desafios que hoje se lhe colocam.

Palavras-chave: sindicalismo; movimento de trabalhadores.

\begin{abstract}
Currently the Union issue is at a crossroad from which it will hardly be released without suffering deep damage in its current model. In fact, the traditional trade union movement - even the one which has always claimed as class unionism, has long been showing signs of exhaustion. Taking into consideration Europe and all its social legacy, any reflection on this subject is impossible without, at the same time, covering the main lines of changes that have occurred in Europe since the first decades of the 20th century, in both, socio-occupational plan and in the political sphere and the activity of the State. The European union movement fought for labor rights and participated in the most intense anti-capitalist fights of the 19th century, but ended up taking part of the historical commitment that produced (in the shadow of the welfare state) the "middle classes" and empowered the democratic socialism. At the same time, it was not able to keep up with the dynamic that has transformed labor and subsequent social movements that were out of its control. From the sixties to the present struggle against precariousness and democratic deficits, passing through movements against neoliberal globalization and ending in the new political activism of "cyberspace", the new languages and repertoires that most mobilized the youth in different generations were, or are, relatively lateral experiments on the Union and its leaders. Will the intensity of the current crisis and its overwhelming pressure on the world of work - and the European middle classes - arouse the unions and pull them out of the bureaucratic straitjacket in which they were stuck? Starting from this reality, this text intends to draw a critical balance of the world unionism and question the challenges that are faced today.
\end{abstract}

Keywords: unionism; social labor movements. 


\section{A crise do Estado social europeu}

Embora se saiba que não existe um modelo europeu único, pode, genericamente, considerar-se que os traços que guiaram as principais economias europeias ao longo do chamado modelo fordista passaram por um equilíbrio entre o Estado e o mercado, conjugado com um contínuo crescimento económico com políticas económicas keynesianas de procura do pleno emprego e um equilíbrio entre a produção industrial e a redistribuição. Tal sistema estimulou o aumento do poder de compra e a sustentabilidade das políticas de segurança e proteção social, configuradas no Estado-providência, que se apresentou ao mundo como o principal modelo de sucesso económico e de bem-estar geral. O Estado-providência europeu tornou-se uma espécie de contraparte do modelo de "socialismo soviético", um e outro com pretensões a servir de "farol" de progresso e emancipação dos trabalhadores e da humanidade, ao longo do período entre 1945 e 1975, por isso mesmo já batizado pelos "gloriosos trinta anos" de bem-estar social.

A Europa (particularmente os países da Europa do Norte) reunia as vantagens dos EUA com todos os seus avanços tecnológicos e cultura democrática com políticas sociais protetoras dos mais desapossados. Efetivamente, a relação salarial fordista de produção, que se generalizou no pós-guerra - embora, evidentemente segundo dinâmicas nacionais muito distintas consoante as regiões e os regimes de cada país - é indissociável do papel do Estado, pois ela traduziu a passagem de uma relação de trabalho concorrencial e puramente mercantil para um modelo juridicamente regulado, dando lugar à ideia de que: "a garantia de emprego e a noção de emprego - o contrato indeterminado - e a proteção social estão na origem da chamada cidadania social na Europa ocidental do pós-guerra" (OLIVEIRA; CARVALHO, 2010, p. 27).

O choque petrolífero de 1973-74 provocou receios sérios de uma doença súbita e preocupante para a Europa: a "euroesclerose", relacionada com a perda de confiança no modelo e seu futuro prospetivo, já então com as economias asiáticas em pano de fundo, mostrando os primeiros riscos de desmantelamento do modelo e dando lugar a um discurso que passou a secundarizar o papel das empresas e da indústria em benefício da economia financeira e do monetarismo. Como assinalou João Cravinho, o olhar passou a centrar-se, na perceção comum, "quase exclusivamente no lado social do modelo, representado pelo Estado social, acompanhado pelas políticas de redistribuição financiadas pela elevada taxação" (CRAVINHO, 2007, p. 14). Esta leitura assentava na ideia de que o desempenho económico da Europa era francamente deficitário por 
referência aos EUA e, ao que se supunha, por maioria de razão o seriam perante as economias emergentes do continente asiático assentes nos baixos salários. A crescente pressão que se foi exercendo sobre as atribuições sociais do Estado ${ }^{3}$ deu lugar a novas fórmulas e propostas para a redução da intervenção estatal na economia, suscitando novas linhas de argumentação em que o chamado "princípio da subsidiariedade", isto é, a ideia de restringir ao mínimo indispensável a intervenção do Estado - quer na atividade empresarial quer mesmo nos programas assistencialistas ou nas políticas de educação e saúde -, que apenas se justificava enquanto complemento da sociedade e dos agentes económicos, ou seja, somente nos casos em que a iniciativa privada se revelasse incapaz de cumprir as funções consideradas fundamentais para o interesse público.

Os modelos "sociais" ou de regulação que marcaram a Europa passaram por ciclos muito distintos e revelaram tensões e conexões muito complexas, não obstante a presença dominante de uma dada fórmula em cada conjuntura. Nesse processo, sempre oscilaram tendências contrárias ou complementares entre a primazia dos mercados e a do Estado. É, por isso, importante não esquecer que o que ocorreu no continente europeu e no Ocidente em geral não foi, de modo nenhum, um processo uniforme e simultâneo em todos os países. Muito embora a economia de mercado tenha começado a aumentar a sua força perante os Estados soberanos (o desequilíbrio de poderes, a força política, militar, tecnológica etc., de cada Estado), bem como a solidez das suas instituições e capacidade competitiva no xadrez internacional, daí resultaram dinâmicas muito discrepantes. Podem, por exemplo, fazer-se distinções muito claras entre o modelo das sociais-democracias vigente nos países nórdicos, a tradição corporativista de países como a Alemanha, a França e a Itália e o modelo mais liberal vigente no Reino Unido (e nos EUA), sendo no entanto de destacar que, já desde os anos noventa do século 20 se vem colocando em causa a ideia de que o modelo neoliberal seja o desenlace inevitável da crise do Estado-providência (JESSOP, 1990; ESPING-ANDERSEN, 1996; SANTOS E FERREIRA, 2001). Não se trata, portanto, de pensarmos em termos de uma simples viabilidade ou inviabilidade do "Estado social", mas antes de situar a reflexão no quadro das transformações socioeconómicas e políticas mais profundas que marcam a mudança histórica, em particular nos últimos dez anos. Sendo o capitalismo um sistema dotado de grande complexidade e dinamismo, o modo como a sua infraestrutura económica se combina e conflitua com o sistema democrático (a democracia formal) tem obedecido sempre a contradições, tensões e com-

${ }^{3}$ Fortemente potenciadas pelo triunfo político do modelo neoliberal consubstanciado nas vitórias de Ronald Reagan e Margaret Tatcher, mas que teve sequência nos governos socialistas e sociais-democratas que se lhe seguiram. 
promissos mais ou menos instáveis, sendo hoje duvidoso até quando e em que condições a democracia e o capitalismo constituem um binómio compatível ao crescimento das forças produtivas ou se, pelo contrário, intensificam os seus antagonismos e dão lugar a ruturas radicais e imprevisíveis (SANTOS, 2005 e 2011). Seja como for, a história mostra-nos que não há modelos monolíticos que se seguem uns aos outros, mas sim soluções sempre compósitas, transitórias e de duração indefinida.

Num período como o que temos vivido nos últimos anos no contexto europeu, de atrofiamento do welfare state, vimos como o modelo keynesiano foi substituído pelo novo mercantilismo global - inspirado no princípio shumpeteriano e no neoliberalismo de Milton Friedman e da Escola de Chicago - segundo o qual os mercados são dotados de uma capacidade "natural" de autorregulação e o monetarismo é o motor do crescimento, cabendo ao Estado sobretudo assegurar as condições da boa concorrência. Esse processo, apesar das suas particularidades em países diferentes, traduziu-se em três traços fundamentais: a descentralização da ação estatal para as escalas local ou transnacional; a maior focalização na esfera laboral, nomeadamente nas políticas de formação profissional e na flexibilização (lean production); a aposta na "governança", em geral acompanhada por processos de privatização e terceirização (subcontratação, na terminologia de Portugal) em diversos sectores e serviços públicos (SILVA, 2009).

O que vem sucedendo na Europa nas últimas décadas - e mais ainda desde 2008 - prende-se igualmente com um conjunto de transformações arrastadas pelas mesmas forças que estão a fustigar as economias e os Estados desde os anos oitenta do século passado, ou seja, a globalização neoliberal. $\mathrm{O}$ fraco crescimento e a recessão económica, o envelhecimento demográfico, o poder crescente da economia financeira em detrimento das políticas produtivas, são alguns dos aspetos que contribuíram para o aumento do défice público, o endividamento externo e a insustentabilidade do modelo de Estado social a que nos habituámos nos países europeus. Mas mais do que isso, os critérios errados e precipitados que presidiram a criação da Moeda Única (apenas em benefício da Alemanha), a especulação financeira e o papel descontrolado das agências de rating, têm vindo a empurrar alguns países para a ruína, como Portugal e a Grécia, e a própria União Europeia está em risco de desmantelamento.

Nestas condições, parece hoje evidente a impossibilidade de um regresso à velha matriz do Estado-providência tal como existiu no passado. O que está em curso é uma mudança profunda e estrutural, tornando impossível o retorno à situação dos "gloriosos trinta anos". As opções políticas a adotar terão de escolher entre a intensificação do mercantilismo "selvagem", correndo o risco de fazer explodir as desigualdades, a miséria e as injustiças sociais, com a consequente generalização da conflitualidade, ou dar continuidade à tradição humanista e 
solidária inscrita na história da Europa, reerguendo um modelo social adequado à nova realidade. Por isso, alguns especialistas sugerem um cenário de recriação da fórmula antiga do Estado-providência, referindo-se a um "Estado neo-social", cenário que, a confirmar-se, pressupõe a emergência de um novo paradigma socioeconómico que poderá inspirar-se, "quer em ideologias do passado entretanto reformuladas, quer híbridas mais ou menos consistentes, quer até em propostas realmente originais [que] poderão vir a ser esgrimidas no espaço público num futuro mais próximo do que muitos julgariam possível apenas há uns meses atrás" (SILVA, 2009, p. 38). Seja como for, o caso português oferece-se como um exemplo particular, um case study que merece ser pensado à luz das suas especificidades. Para o compreendermos em profundidade importa tomar como questão central as mudanças em curso no campo laboral, mudanças que se traduzem na crescente precariedade e desvalorização do trabalho assalariado e dos direitos sociais a ele associados. É a própria coesão social e o património humanista de raiz europeia que hoje estão ameaçados. Vejamos alguns dos contornos desse processo nas últimas décadas.

\section{Trabalho e precariedade}

Como é sabido, o campo laboral constitui, por definição, o centro vital das sociedades industriais desde a sua origem. O trabalho, que ao longo dos séculos havia sido objeto de desprezo e exclusão, tornou-se, desde finais do século 18 o pilar decisivo de estruturação do capitalismo moderno. Porém, o processo de dignificação do trabalho assalariado não foi exatamente o resultado de uma evolução paulatina e harmoniosa, antes decorreu sob o signo da conflitualidade e das lutas sociais protagonizadas pela classe trabalhadora e movimento operário. Daí que a burguesia emergente do século 19 se tenha preocupado com os impactos de uma "questão social" que ameaçava as promessas do liberalismo e da economia emergente. Essa "grande transformação" (POLANYI, 1980) que viria a consolidar o capitalismo moderno fundou-se em sucessivas tensões suportadas não só pelo antagonismo capital-trabalho, mas também pela complexidade das articulações entre a comunidade, o mercado e o Estado, sendo que, em todos esses processos o campo sindical ocupou um papel decisivo. Em Portugal, na Europa e no mundo industrializado, muitos movimentos sociais, velhos e novos, se conjugaram e por vezes se misturaram contribuindo decisivamente para as transformações profundas que ocorreram ao longo dos últimos dois séculos (THOMPSON, 1987; TILLY, 1996; TOURAINE, 2006; SANTOS, 2011). 
Durante muitos séculos, os mercados foram apenas acessórios dos sistemas sociais, mas aos poucos ganharam ascendente sobre a produção e a distribuição, submetendo-as cada vez mais à lógica das transações monetárias e da motivação pelo lucro e retirando sentido ao velho princípio das relações de troca e da reciprocidade. $\mathrm{O}$ trabalho, a terra e o dinheiro, sendo parte do sistema económico, são organizados através do mercado, mas não são mercadorias. $\mathrm{Na}$ verdade, a valorização do trabalho ao longo do século 20, em especial na Europa ocidental, com todas as conquistas sociais alcançadas após a $2^{\mathrm{a}}$ Guerra Mundial, foi justamente ao encontro dos princípios iluministas, mas essas vitórias das classes trabalhadoras e próprio triunfo do Estado-Providência só ocorreram graças ao trabalho de organização, mobilização e de luta do movimento sindical internacional que culminou com a afirmação do primado do Estado sobre o mercado, modelo que vigorou durante as chamadas três décadas de ouro dos direitos sociais.

Ao longo dos últimos trinta anos, sob o impulso da globalização da economia e do paradigma neoliberal (REIS, 2009), a esfera laboral foi sendo palco de novas dinâmicas de mudança a nível global, muito embora os seus efeitos, contornos e formas tenham sido, e continuem a ser, muito variadas, segundo as regiões do mundo em consideração. Podem sintetizar-se nos seguintes pontos: 1) estagnação e declínio do sector secundário e com ele a redução do emprego industrial em favor do sector terciário e da informação; 2) aumento dos níveis de sindicalização entre as categorias da classe média, nomeadamente no funcionalismo público, mas o mesmo acentuou a lógica neocorporativista; 3) novas divisões internas no seio dos assalariados, entre manuais e não manuais, entre tecnocratas e burocratas, entre novas e velhas profissões, como resultado da profissionalização da gestão, da revolução tecnológica e do impacto das novas tecnologias da comunicação - NTC; 4) crescente diferenciação interna da classe média assalariada com a emergência de novas tensões e clivagens, novas lógicas de fechamento, padrões de consumo e estilos de vida; 5) aumento da pressão dos mercados e da economia financeira, com a mercadorização a atingir todas as esferas da vida (pública e privada); 6) intensificação da flexibilização, multiplicação dos vínculos contratuais, com o crescimento de formas de trabalho antes consideradas "atípicas" como a subcontratação, o trabalho clandestino, os contratos precários, a maior facilidade de despedimento, o aumento do desemprego nos sectores qualificados e não-qualificados (ESPING-ANDERSEN, 1996; ESTANQUE E COSTA, 2011; CARMO, 2010).

Os impactos do desenvolvimento tecnológico no tecido produtivo português defrontam-se com as resistências de uma mentalidade empresarial conservadora, onde se reflete a força das diferenças de estatuto e das hierarquias de poder, aspetos particularmente vincados na nossa sociedade. As mudanças que, 
num período mais recente, têm vindo a ser operadas são dificilmente percetíveis de forma generalizada pelas grandes organizações. Nas empresas de maiores dimensões, as políticas de gestão flexível, de um modo geral, apenas têm tradução ao nível dos quadros superiores e das estruturas de topo. No entanto, é preciso dar a devida importância a aspetos como a absorção pelo mercado de emprego de novas competências em educação.

Os resultados da crescente flexibilização e recomposição do tecido produtivo têm-se traduzido em novas segmentações onde se desenham claras diferenças na geometria empresarial, mas onde pontifica ainda uma grande dificuldade de renovação.

Com a entrada no novo século, os temas da segmentação, flexibilização e precarização do trabalho foram ganhando importância no debate académico e no terreno da conflitualidade sociolaboral. Serge Paugam (2000) analisou esse processo mostrando o acentuar da precariedade laboral. Durante muito tempo pensou-se que o trabalho traria satisfação baseada num equilíbrio entre: o próprio ato de trabalhar e a autonomia que ele conferia; a retribuição económica obtida através do trabalho; e o reconhecimento social, ou status, realizado por via dele. Enquanto esse equilíbrio se manteve, foi possível garantir ao trabalhador uma integração assegurada (1), que correspondia a uma dupla segurança, por um lado, o reconhecimento material e simbólico retirado do trabalho e, por outro, a proteção social associada a um emprego estável. Porém, com a entrada no novo milénio esse modelo foi dando lugar a novas formas, que colocam o trabalhador em situações cada vez mais vulneráveis: - integração incerta (2): satisfação no trabalho com instabilidade do emprego, como é o caso das empresas em dificuldades, mais ou menos condenadas à redução de efetivos ou ao encerramento; - integração laboral (3): insatisfação no trabalho, mas com estabilidade do emprego, como acontece, por exemplo, em empresas que sofreram reestruturações do sistema produtivo mas permanecem sólidas; - integração desqualificante (4): insatisfação no trabalho com instabilidade do emprego, corresponde à forma mais marcada pela precariedade profissional, como é o caso de muitas empresas multinacionais, onde existe o perigo constante de deslocalização.

É sobretudo entre os assalariados próximos da integração incerta e da integração laboral que mais penetra o sentimento de medo perante as formas de poder despótico que proliferam nas empresas, associadas às múltiplas formas de terceirização e prestação de serviços a que recorrem as forças da economia e do mercado. Por seu lado, os assalariados próximos da integração desqualificante sentem um crescente distanciamento em relação à vida colectiva da empresa, e as suas orientações pautam-se pela desilusão e frustração, fechando-se em si próprios ou extrapolando esta atitude para a esfera da vida familiar. Apesar de muitos assalariados considerarem que os motivos de contestação são, 
hoje, mais fortes do que no passado, a frustração induzida pela precariedade, favorece a procura de soluções individuais a nível profissional, dificultando a ação colectiva. Porém, a reflexão sobre a tendência para a proletarização de segmentos significativos do emprego, designadamente no setor dos serviços e em segmentos da classe média assalariada, pode contribuir para uma nova tomada de consciência dos atores sociais e dos cidadãos capaz de abrir novas perspetivas às lutas organizadas (cf. HUWZ, 2003; ALVES, 2009; STANDING, 2009 e 2011; GIOVANOPOULOS; DALAKOGLOU, 2011; GRESH, 2011).

À semelhança do que ocorreu no século 19 - cujo processo de mercantilização significou a reconversão da economia de mercado para a sociedade de mercado, com o despojamento do trabalho do seu carácter humano e da sua dignidade - as atuais tendências parecem evoluir para uma "questão social" tão contraditória e conflitual como a realidade europeia de há duzentos anos. Por outras palavras, cada tendência social quase sempre dá origem à sua contraparte, pelo que, pode-se dizer, um período de apatia e resignação pode se reverter num ciclo de agitação e rebeldia, como de resto ocorreu em diversos pontos do globo no ano de 2011. Na Europa do século 20 assistimos à edificação do Estado-providência ao longo dos "trinta gloriosos anos", que constituiu até agora a mais interessante experiência de bem-estar social da modernidade ocidental. A sua contraparte resultou na intensificação do ataque aos direitos sociais e laborais, desenhando um cenário de retrocesso e agressão aos direitos do trabalhador e o resultado mais visível é o desmantelamento do antigo modelo providencial. Com efeito, sessenta anos decorridos, o modelo do Estado social europeu ameaça desmoronar-se com todas as consequências que daí podem advir, a começar pelo aumento exponencial do desemprego e a culminar no empobrecimento das classes médias e da classe trabalhadora no seu conjunto (ESTANQUE, 2012).

O paradigma económico que hoje domina a Europa e o mundo repousa numa conceção da vida, da economia e dos mercados que omitem o papel das estruturas socioeconómicas sobre a vida das pessoas em favor do princípio liberal e individualista, que deixa à responsabilidade de cada um (inclusive os desempregados) a obrigação de mostrar o seu potencial "empreendedor". Na verdade, este "guião" neoliberal transporta uma visão ideológica que concebe o trabalho como mera mercadoria como que num regresso ao passado, aos princípios do século 19. O direito trabalhista está sendo desmantelado e a relação salarial torna-se objeto de regulação civilista, tratando como partes iguais aquilo que é diferente e ignorando a secular assimetria de poder capital-trabalho. Uma tal conceção só pode entender-se à luz das transformações sociais a que vimos assistindo desde há várias décadas e cujo epicentro é justamente a esfera laboral. Vivemos um período delicado, uma crise que evidencia traços estruturais e está a dar lugar a uma sucessão de medidas de austeridade que parecem querer 
instalar-se por longos anos. É bem real a ameaça de vermos ruir todo o edifício de conquistas civilizacionais que, desde o século 18, se afirmaram na Europa e onde a atividade profissional se impôs como principal fonte de status, de dignidade e de coesão social. Porém, a desvalorização do trabalho não impede que o mesmo permaneça como uma atividade decisiva para a construção identitária, um fator de afirmação de qualificações, uma fonte de emanação de direitos e de cidadania. $\mathrm{O}$ trabalho persiste como uma dimensão fulcral de sociabilidade que liga o indivíduo à natureza e à sociedade. Por esse motivo, devemos assumir que a retirada de condições de segurança e estabilidade nas relações laborais só pode ter como consequência o esgaçar do próprio tecido social, com todo o rol de riscos que isso comporta, tanto para a atividade económica como para a vida das pessoas. O velho «contrato social» está a rasgar-se em benefício da parte mais poderosa da relação salarial (o empregador).

\section{Sindicalismo de classe média}

O modelo de Welfare state que atrás foi referido, de matriz europeia, carregou consigo um processo social de âmbito mais vasto cuja solidez derivou em larga medida do crescente aumento dos serviços, onde se inscreve o trabalho sindical do setor público do qual o sindicalismo docente é uma componente importante. Importa pensar tais processos ao longo da história europeia muito embora sem esquecer que o "padrão" a que nos referimos tenha mais tradução na realidade dos países do norte da Europa do que nas periferias do sul, como é o caso de Portugal. De resto, mesmo os países do hemisfério Sul, como os da América Latina, têm perseguido estratégias desenvolvimentistas e políticas sociais que tomam como referência a experiência europeia, ainda que a visão "eurocêntrica" não deva ser esquecida (ALDEIA; ESTANQUE, 2011). ${ }^{4}$

É, portanto, a essa luz que faz sentido pensar um sindicalismo de classe média. $\mathrm{O}$ aperfeiçoamento e a planificação administrativa expandiram o sector burocrático, enquanto cresciam os impactos da educação, da ciência e da técnica e o permanente investimento nas qualificações, estimulando novas camadas de burocratas e tecnocratas, que foram engrossando a classe média. Para além disso, a profissionalização da gestão, a expansão das sociedades anónimas, a multi-

${ }^{4}$ A qual se estende da perspetiva colonial e dominante ao próprio pensamento crítico, inclusive de raiz marxista, também ele veículo de premissas eurocêntricas. Veja-se a propósito Aldeia e Estanque (2011). 
plicação de novas profissões, novas formas contratuais e condições de trabalho muito diversificadas deram lugar a transformações de grande impacto na coesão da sociedade no seu todo. A escola, a vida profissional, o negócio familiar ou individual, os novos direitos e condições de promoção e de carreira, a evolução salarial e a profunda alteração na estrutura global do emprego consolidaram a ideia de uma classe média sólida, em crescimento e que se assumia cada vez mais como o núcleo fundamental e decisivo da coesão social.

O aumento rápido do sector dos serviços, o desenvolvimento tecnológico, lado a lado com o novo enquadramento dos aparelhos de regulação social, transformaram profundamente as sociedades ocidentais contribuindo para a emergência do modelo fordista, gerador de estabilidade do emprego e da progressão de carreiras, o que, somado à melhoria do poder de compra da força de trabalho no seu conjunto - sobretudo entre os profissionais mais qualificados e os funcionários de colarinho branco -, contribuiu para intensificar os fluxos de mobilidade social ascendente. Mesmo quando tais fluxos não eram, de facto, tão substanciais como pareciam, geraram um efeito simbólico que estimulou o entusiasmo de amplos segmentos dos trabalhadores, criando assim grandes expectativas de ascensão social (voltarei a este ponto na parte final, a propósito da sociedade portuguesa).

Com a crescente fragmentação das classes e a multiplicação das desigualdades e diferenças (étnicas, culturais, raciais, linguísticas, de género, etc.), o movimento sindical ganhou poder institucional e negocial ao mesmo tempo que perdeu capacidade de mobilização junto de um operariado cada vez mais enfraquecido. Os trabalhadores manuais conseguiram mais segurança, mais direitos e mais poder de compra, aproximando-se em muitos países dos padrões de consumo da classe média. E entretanto sucessivas gerações de novos técnicos e funcionários, muitos deles filhos da classe trabalhadora manual, acediam a níveis mais elevados de escolaridade e alcançavam posições em empregos administrativos de diversos tipos. Desta forma, o crescimento da classe média caminhou de par com a sua dispersão interna e da fragmentação da classe operária, igualmente sujeita às condicionantes derivadas dos vastos investimentos em educação, em ciência e em tecnologia. Com tudo isto, a velha luta de classes que havia sido incubada nos grandes polos de concentração industrial, com especial relevo para as indústrias têxtil, siderúrgica e metalomecânica, foi cedendo o lugar a subjectividades, atitudes, comportamentos e padrões de vida mais marcados pelo individualismo, pela adaptação e pelo consumo.

No entanto, não se deve esquecer que o sindicalismo desde sempre foi marcado pela pluralidade de lógicas de ação, de formas organizativas e de referências ideológicas. Alguns teóricos clássicos do movimento sindical, como o casal S. \& B. Webb (1976), acentuaram acima de tudo a vertente economicista 
e funcional dos sindicatos - o chamado "sindicalismo de mercado" -, que efectivamente deu lugar às modalidades mais corporativas e institucionais do sindicalismo moderno, enquanto outras correntes colocam antes a ênfase na ideia do sindicalismo como movimento social, que assenta na conjugação de aspetos como a defesa da democracia direta, o autoempoderamento e a consciencialização perante os problemas mais amplos da classe.

O sindicalismo de movimento pode, assim, definir-se pelos seguintes traços: i) a afirmação de identidades e interesses colectivos dos trabalhadores; ii) a tensão entre a defesa dos interesses da classe trabalhadora e as lutas mais gerais contra a opressão; iii) a prioridade dada à relação "normal" de emprego caracterizada pelos contratos de emprego permanente, onde a actividade grevista teve maior impacto; e, finalmente iv), a representação da classe trabalhadora no seu conjunto e a sua organização em bases nacionais e não internacionais (MELUCCI, 1996; DIBBEN, 2004). É claro que, mesmo entre os que se reclamam de "sindicalismo combativo" ou "sindicalismo de classe" persistem as constantes polémicas e debates, que, aliás, acompanharam a história do sindicalismo desde há mais de duzentos anos. Por outro lado, foram constantes as disputas em torno das instâncias de filiação, incluindo a interferência de forças partidárias, correntes políticas e as pressões institucionais de todos os tipos. A própria internacionalização do campo sindical foi desde sempre pautada pela controvérsia, como mostram os encontros das Internacionais Operárias, de finais do século 19 e que definiram as principais divisões entre famílias ideológicas no campo da esquerda (social democracia, socialismo, comunismo, etc.). Acresce que tais divisões continuam presentes na atualidade, como prova o processo de criação e de fusão das centrais e federações sindicais na Europa e no Mundo ${ }^{5}$. No caso português a própria $\mathrm{CGTP}^{\mathrm{IN}}{ }^{6}$ tem recusado, até agora, a adesão à recém-criada CSI, devido em larga medida ao passado de estreita colaboração com a FSM (estrutura herdada do campo soviético), como recentemente foi revelado por um dos seus antigos dirigentes que entrou em ruptura com a orientação dominante (LANÇA, 2010).

Num momento em que a crise económica, o desemprego e a precariedade

${ }^{5}$ A Confederação Sindical Internacional (CSI), que é hoje a maior central internacional, fundada em 2006, resultou da fusão entre a Confederação Internacional de Sindicatos Livres (CISL) e a Confederação Mundial do Trabalho (CMT). Entretanto, a Federação Sindical Mundial (FSM), de raiz soviética, mantém-se de fora e continua a influenciar algumas das referidas divisões, apesar da queda do muro de Berlim ter ocorrido há mais de 20 anos (e talvez por causa disso).

${ }^{6}$ Confederação Geral dos Trabalhadores Portugueses - Intersindical Nacional, é a central sindical mais representativa (representando cerca de dois terços dos assalariados) e mais combativa em Portugal, tendo ao longo dos tempos sido muito influenciada pelo Partido Comunista Português e hegemonizada pela sua corrente mais ortodoxa. 
ganham novos contornos dramáticos, instala-se a dúvida quanto aos caminhos de saída desta crise sem fim à vista. Se o capitalismo financeiro e a globalização neoliberal que a provocaram estão apenas à espreita de uma nova oportunidade, e se as instituições da UE (Parlamento e Comissão Europeia) estão cada vez mais prisioneiras das próprias tramas em que se deixaram enredar, talvez seja chegada a hora de uma outra vaga de solidariedade, um movimento sindical de novo tipo, numa nova união com as redes e movimentos sociais de todos os tipos - há quem fale no novo precariado emergente (STANDING, 2011) ou de um novo radicalismo de classe média (ESTANQUE, 2012) - e onde muitos setores da classe média em declínio na Europa e em Portugal certamente irão participar através de formas de ação e de ativismo que deverão transcender a tradicional lógica corporativista e mercantilista que, sobretudo desde o pós-Guerra, marcou diversas gerações de funcionários e servidores ao longo de décadas.

\section{REFERÊNCIAS}

ALDEIA, João; ESTANQUE, Elísio. Os sujeitos que nunca foram históricos: uma crítica do marxismo eurocêntrico. Revista eletrônica INTERthesis, jul. 2011. Universidade Federal de Santa Catarina, Brasil. Disponível em: $<$ http://www.periodicos.ufsc.br/index. php/interthesis/>. Acesso em: 09/12/2012.

ALVES, Giovanni. A Condição de Proletaridad. Londrina: Praxis, 2009.

CARMO, Renato Miguel do (Org.). Desigualdades Sociais 2010. Estudos e Indicadores. Lisboa: Observatório das Desigualdades/ Editora Mundos Sociais, 2012.

CRAVINHO, João. A reforma do modelo socioeconómico europeu: deve a Europa reforçar-se para emular o modelo europeu? In: BOAVIDA, Nuno; NAUMANN, Reinhard (Orgs.). O Estado e a Economia: o modelo económico europeu no século XXI. Lisboa: Fundação Friedrich Ebert, 2007.

DIBBEN, Pauline. Social movement unionism In: HARCOURT, Mark; GEOFFREY, Wood (Eds.). Trade Unions and Democracy. Manchester: Manchester University Press, 2004. p. 280-392.

ESPING-ANDERSEN, Gøsta (Ed.). Welfare States in Transition: National Adaptations in Global Economies. Londres: Sage, 1996.

ESTANQUE, Elísio. A Classe Média. Ascensão e Declínio. Lisboa: Fundação Francisco Manuel dos Santos/Relógio d'Água, 2012.

ESTANQUE, Elísio; COSTA, Hermes (Eds.). O Sindicalismo Português e a Nova 
Questão Social: crise ou renovação? Coimbra: Almedina, 2011.

GIOVANOPOULOS, Christos; DALAKOGLOU, Dimitris. From ruptures to eruption: a genealogy of the December 2008 revolt in Greece. In: VRADIS, Antonis; DALAKOGLOU, Dimitris (Eds.). Revolt and Crisis in Greece: between a Present Yet to Pass and a Future Still to Come. London: AK Press \& Occupied London, 2011. p. 91-114.

GRESH, Alain. O que muda com o despertar árabe. Dossier 06 “O Despertar do Mundo Árabe”, Jornal Le Monde Diplomatique - Brasil, ano 1, jul./ago. 2011.

HUWS, Ursula. The Making of a Cybertariat: virtual work in a real world. New York: Monthly Review Press, 2003.

JESSOP, Bob. State Theory: putting the capitalist state in its place. Cambridge: Polity Press, 1990.

LANÇA, Florival. Inter Nacional. Porto: Profedições, 2010.

LECCARDI, Carmen. Por um novo significado do futuro: mudança social, jovens e tempo. Tempo Social-Revista de Sociologia da USP, v. 17, n. 2, p. 35-57, 2005.

MELUCCI, Albert. Challenging Codes. Collective action in the information age. Cambridge: Cambridge University Press, 1996.

OLIVEIRA, Luísa; CARVALHO, Helena. Regulação e mercado de trabalho: Portugal e a Europa. Lisboa: Edições Sílabo, 2010.

PAUGAM, Serge. Le Salarié de la Précarité. Paris: PUF, 2000.

POLANYI, Karl. A grande transformação: as origens da nossa época. Rio de Janeiro: Campus, 1980.

REIS, José. Os caminhos estreitos da economia portuguesa: trabalho, produção, empresas e mercados. Revista Crítica de Ciências Sociais, v. 85, p. 5-21, 2009.

SANTOS, Boaventura de Sousa. Portugal: ensaio contra a autoflagelação. Coimbra: Editora Almedina, 2011.

SANTOS, Boaventura de Sousa. Fórum Social Mundial: Manual de Uso. Porto: Afrontamento, 2005.

SANTOS, Boaventura de Sousa; FERREIRA, Sílvia. A reforma do Estado-Providência entre globalizações conflituantes. In: HESPANHA, Pedro; CARAPINHEIRO, Graça (Orgs.). Risco Social e incerteza: pode o Estado social recuar mais? Porto: Afrontamento, 2001. p. 177-225.

SILVA, Filipe Carreira da. Metamorfoses do Estado: Portugal e a emergência do Estado neo-social. In: CARMO, Renato Miguel; RODRIGUES, João (Orgs.). Onde pára o Estado? Políticas públicas em tempos de crise. Lisboa: Edições Nelson de Matos, 2009. p. 19-51.

STANDING, Guy. Work after globalization. Cheltenham: Edward Elgar Publishing, 2009. 
STANDING, Guy. Precariat: the new dangerous class. London: Boolmsbury Academic, 2011.

THOMPSON, E. P. A formação da classe operária inglesa. Rio de Janeiro: Paz e Terra, 1987.

TILLY, Charles. As Revoluções Europeias 1492-1992. Lisboa: Presença, 1996.

TOURAINE, Alain. Na fronteira dos movimentos sociais. Sociedade e Estado, v. 21, n. 1, p. 17-28, 2006.

WEBB, Sidney; WEBB, Beatrice. The History of Trade Unionism. New York: AMS Press, 1976 [1898].

Texto recebido em 27 de setembro de 2012.

Texto aprovado em 15 de outubro de 2012. 